\title{
External Groundwater Alleviates the Degradation of Closed Lakes in Semi-Arid Regions of China
}

\author{
Jiaqi Chen ${ }^{1}$, Jiming $\mathrm{Lv}^{1} \mathbb{C}$, Ning $\mathrm{Li}^{2, *} \mathbb{C}$, Qingwei Wang ${ }^{1}$ and Jian Wang ${ }^{1} \mathbb{C}$ \\ 1 School of Computer and Information, Hohai University, Nanjing 210098, China; jiaqichen@hhu.edu.cn (J.C.); \\ ljmhhu@hhu.edu.cn (J.L.); qingwei@hhu.edu.cn (Q.W.); jianwang@hhu.edu.cn (J.W.) \\ 2 College of Computer and Information Engineering, Henan University, Kaifeng 475004, China \\ * Correspondence: hedalining@henu.edu.cn; Tel.: +86-13283780125
}

Received: 18 November 2019; Accepted: 18 December 2019; Published: 20 December 2019

\begin{abstract}
There are a large number of lakes with beaded distribution in the semi-arid areas of the Inner Mongolian Plateau, and some of them have degraded or even disappeared during the past three decades. We studied the reasons of the disappearance of these lakes by determining the way of replenishment of these lakes and the impact of the natural-social environment of the basin, with the aim of saving these gradually disappearing lakes. Based on remote sensing image and hydrological analysis, this paper studied the recharge of Daihai Lake and Huangqihai Lake. The deep learning method was used to establish the time-series of lake evolution. The same method was combined with the innovative woodland and farmland extraction method to set up the time-series of ground classification composition in the basins. Using relevant survey data, combined with soil water infiltration test, water chemical, and isotopic signature analysis of various water bodies, we found that the Daihai Lake area is the largest in dry season and the smallest in rainy season and the other lake is not satisfied with this phenomenon. In addition, we calculated the specific recharge and consumption of the study basin. These experiments indicated that the exogenous groundwater is recharged directly through the faults at the bottom of Daihai Lake, while the exogenous groundwater is recharged in Huangqihai Lake through rivers indirectly. Large-scale exploitation of groundwater for agricultural irrigation and industrial production is the main cause of lake degradation. Reducing the extraction of groundwater for agricultural irrigation is an important measure to restore lake ecology.
\end{abstract}

Keywords: remote sensing; deep learning; Daihai Lake; Huangqihai Lake; lake degradation

\section{Introduction}

Lakes are generally facing rapid decline in the arid and semi-arid regions of the world [1-4]. The Inner Mongolia Plateau is a semi-arid area with much more evaporation than precipitation [5], but there are hundreds of lakes with an area of more than $1 \mathrm{~km}^{2}$ distributed on the plateau [6], such as the Daihai Lake, Huangqihai Lake, Dali Lake, and Wuliangsuhai Lake. These lakes are mainly distributed in a bead chain shape in the Altun boreal margin of Yinshan mountain fracture, which is one of the two giant faults in the China zone $[7,8]$. Although the area of these lakes of the plateau has decreased by 30.3\% between 1987 and 2010 [9], the value was even below 35.3\% in Central Asia, another typical arid and semi-arid area, from 1990 to 2007 [6]. In order to figure out this phenomenon, determining the recharge and discharge relationship of lakes is a key step.

Faced the situation of shrinking lakes, there are two different perspectives on the relationship between water recharge and emissions. Firstly, local precipitation is the only source of recharge for these lakes. The supply of lakes receives rivers and groundwater runoff, all of which come from region rainfall in the basins [10]. Secondly, local precipitation cannot recharge groundwater through soil infiltration basically and the main source of recharge of lakes comes from exogenous groundwater. External groundwater 
recharges lakes through fault zones and other transmission channels of water [11,12]. For the first view, researchers calculated the amount of water that recharges into groundwater by precipitation infiltration into soil based on a hydraulic water balance model [13]. Nevertheless, the second view negated this opinion. Researchers verified their standpoint depending on isotope and hydrochemistry analysis. They assumed that groundwater recharge in the basin comes from precipitation, so the weighted average of hydrogen and oxygen isotopes of precipitation should be the same as that of groundwater. However, through experimental analysis, the isotopes of these lakes are obviously different from those of local precipitation and overly high soil salinity in the basin. It has been concluded that precipitation cannot recharge groundwater and lakes to receive a recharging of external water [14].

The current research methods have some shortcomings. The first method assumed that groundwater transportation can only be restricted to the basin. This statement is difficult to satisfy for the plateau region where the basal fault zone develops. In the second method, due to the limited sampling, it is difficult to collect continuous data on changes of lake water, river water, groundwater, and precipitation. The error of data analysis results is large and it is hard to quantitatively determine the groundwater recharge.

To overcome the above problems in previous studies, this paper will study the continuous change of lake area by remote sensing combined with on-site observation data and isotope analysis results to determine whether these lakes accept an external groundwater supplement. Daihai Lake (the third largest inland lake [15]) and Huangqihai lake (formerly the fourth largest inland lake in the Inner Mongolia Plateau [16]) are selected as typical research objects. Moreover, we explored the causes of lake shrinkage and the impact of lake shrinkage on the surrounding ecological environment through the surface changes of the basin.

\section{Study Region}

The Daihai basin and Huangqihai basin are located in Inner Mongolia [17], northwest of China, which possess arid and semi-arid climate environment Figure 1. Daihai and Huangqihai are ancient inland tectonic lakes [18], which were born in the early Quaternary and the distance between the two lakes is about $64 \mathrm{~km}[19,20]$. The main characteristics of this region are a dry climate, sparse precipitation, low surface wetness, and poor ecological stability. The average precipitation and evaporation in this area are 350 to $450 \mathrm{~mm}$ and 1800 to $2100 \mathrm{~mm}$, respectively [21]. Lakes in this difficult natural environment often play an extremely important role in the survival of animals and plants and in human activities.

The area of Daihai basin is about $2312 \mathrm{~km}^{2}$. There are Liangcheng County in the Figure 1 and the total population of the area was about 249000 as of 2013. Daihai is the third largest inland lake in Inner closed Mongolia with a maximum depth of $19.1 \mathrm{~m}$ [22]. Due to the large number of dams in the Daihai basin, a small number of surface paths flow into the lake [23]. Therefore, ground surface precipitation and groundwater are the main water supply for Daihai Lake. The Daihai Lake is almost shrinking every year, which has become the focus of concern for the local people.

The area of Huangqihai basin is about $4480 \mathrm{~km}^{2}$. There are Ulanchab City, Chaharyouyiqianqi County and Chaharyouyizhongqi County Figure 1 [23]. The total population of the region was about 720,000 as of 2012. The lake is a closed lake with an average water depth of three meters in 1986 [24]. The main water supply is surface precipitation, seven seasonal rivers, and groundwater. It was dried out completely in 2006 [16]. The dry Huangqihai Lake has had significant impacts on local biological, ecological, and human activities.

The surface runoffs flowing into Huangqihai Lake come from spring water. The hydrogen and oxygen isotope of groundwater of the basin are significantly different from that of precipitation and spring water. Researchers have stated that the multi-year average value of surface precipitation isotopes in Daihai basin and Huangqihai basin is $\delta^{18} \mathrm{O}=-5.4 \%$, $\delta \mathrm{D}=-35 \%$; in addition, they took 44 groundwater samples (including deep well water and spring water) in the study region, with the average value $\delta^{18} \mathrm{O}=-9.4 \%$ o, $\delta \mathrm{D}=-74.1 \%$ [ [14]. It demonstrates that the main source of supply of the 
lake is groundwater. The massive exploitation of groundwater for agricultural irrigation is the main reason for the shrinking, or even disappearing, of the lake.

In the third section, this paper would explain that we processed the remote sensing images through deep learning method. In the fourth section, the use of remote sensing data would be combined with other related data for analysis. Finally, we discussed and summarized the analysis result.

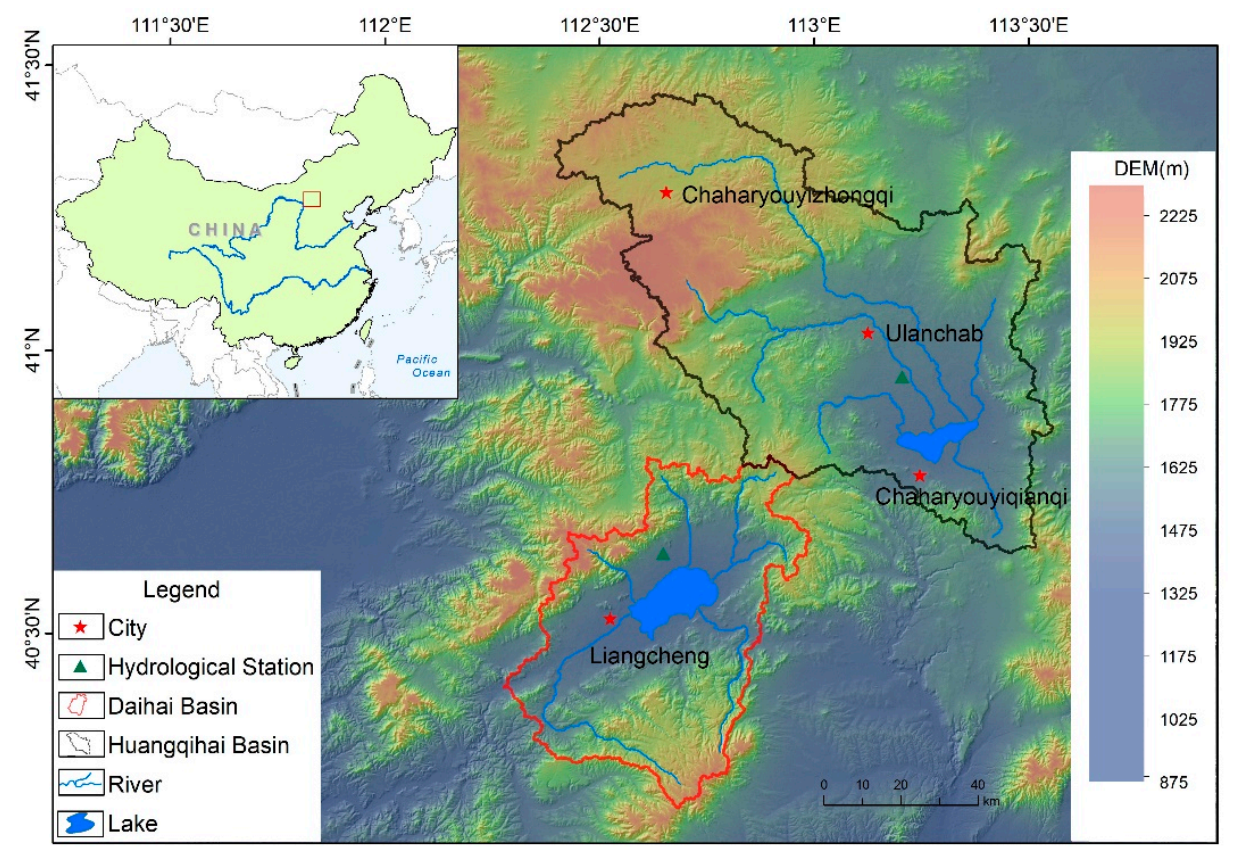

Figure 1. Location and ground observation station distribution map of Daihai basin and Huangqihai basin, China.

\section{Materials and Methods}

\subsection{Flowchart and Datasets}

This study had two fundamental aspects. The processing flowchart is shown in Figure 2. There are four parts in the article (different background colors are used to distinguish). First, the light orange part is the data and method of the article. Second, the light blue part is the main evidence of the analysis. Third, the light yellow part is the main angle of the analysis. Fourth, the light purple part is the expansion analysis of the conclusion of the article. The first was to explore on time-series of two different lakes' surface area. From former study [23], we realized the lakes area had changed dramatically. In this study, three satellites are applied, namely Landsat-5 TM satellite, Landsat-7 ETM+ satellite, and Landsat-8 OLI_TRIS satellite respectively. All Landsat data used in this study are obtained from the United States Geological Survey (USGS) website (http://glovis.usgs.gov/) and the Geospatial Data Cloud, Computer Network Information Center, Chinese Academy of Sciences website (http://www.gscloud.cn/). The necessary image preprocessing steps include radiation calibration and atmospheric correction (top-of-atmosphere, TOA) [25], which are carried out through ENVI 5.3 software. In order to observe the variation of lake area in more detail, we selected 22 remote sensing images about each lake during the past three decades from 1984 to 2018. We selected the images of production time as far as possible from April to June, because the water storage was relatively stable during this period. The lake surface data sources in the study are listed in Table 1. 


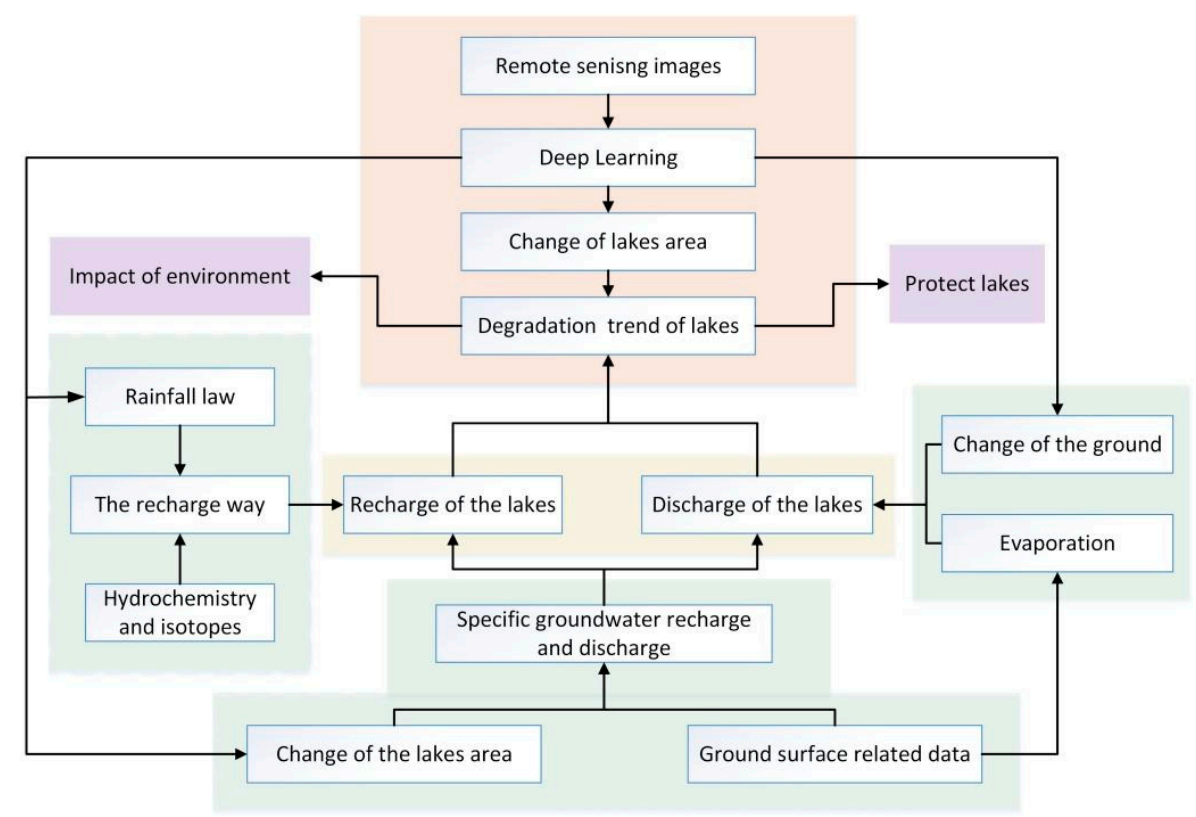

Figure 2. Processing flowchart of this study.

Table 1. Remote sensing data source of study region

\begin{tabular}{|c|c|c|c|c|c|}
\hline \multicolumn{3}{|c|}{ Daihai Lake } & \multicolumn{3}{|c|}{ Huangqihai Lake } \\
\hline Index & Time & Data Source & Index & Time & Data Source \\
\hline 1 & $1984 / 5 / 26$ & Landsat 5(TM) & 1 & $1984 / 5 / 26$ & Landsat 5(TM) \\
\hline 2 & $1986 / 5 / 16$ & Landsat 5(TM) & 2 & $1986 / 5 / 16$ & Landsat 5(TM) \\
\hline 3 & $1987 / 9 / 15$ & Landsat 5(TM) & 3 & $1987 / 9 / 15$ & Landsat 5(TM) \\
\hline 4 & $1989 / 9 / 29$ & Landsat 5(TM) & 4 & $1989 / 9 / 29$ & Landsat 5(TM) \\
\hline 5 & $1990 / 8 / 22$ & Landsat 5(TM) & 5 & $1990 / 7 / 14$ & Landsat 5(TM) \\
\hline 6 & $1992 / 6 / 17$ & Landsat 5(TM) & 6 & $1992 / 6 / 17$ & Landsat 5(TM) \\
\hline 7 & $1994 / 4 / 4$ & Landsat 5(TM) & 7 & $1994 / 4 / 4$ & Landsat 5(TM) \\
\hline 8 & $1996 / 6 / 3$ & Landsat 5(TM) & 8 & $1996 / 6 / 3$ & Landsat 5(TM) \\
\hline 9 & $1998 / 5 / 24$ & Landsat 5(TM) & 9 & $1998 / 5 / 24$ & Landsat 5(TM) \\
\hline 10 & 1999/7/14 & $\begin{array}{l}\text { Landsat7(ETM) } \\
\text { SLC-on }\end{array}$ & 10 & 1999/7/31 & $\begin{array}{l}\text { Landsat7(ETM) } \\
\text { SLC-on }\end{array}$ \\
\hline 11 & $2000 / 5 / 22$ & $\begin{array}{l}\text { Landsat7(ETM) } \\
\text { SLC-on }\end{array}$ & 11 & $2000 / 5 / 22$ & $\begin{array}{c}\text { Landsat 7(ETM) } \\
\text { SLC-on }\end{array}$ \\
\hline 12 & $2002 / 4 / 10$ & $\begin{array}{l}\text { Landsat7(ETM) } \\
\text { SLC-on }\end{array}$ & 12 & $2002 / 4 / 10$ & $\begin{array}{c}\text { Landsat 7(ETM) } \\
\text { SLC-on }\end{array}$ \\
\hline 13 & $2004 / 6 / 9$ & Landsat 5(TM) & 13 & 2004/6/9 & Landsat 5(TM) \\
\hline 14 & $2006 / 6 / 15$ & Landsat 5(TM) & 14 & $2006 / 6 / 15$ & Landsat 5(TM) \\
\hline 15 & $2008 / 9 / 1$ & Landsat 5(TM) & 15 & $2008 / 9 / 1$ & Landsat 5(TM) \\
\hline 16 & $2010 / 5 / 2$ & Landsat 5(TM) & 16 & $2010 / 5 / 2$ & Landsat $5(\mathrm{TM})$ \\
\hline 17 & $2013 / 4 / 15$ & Landsat 8(OLI) & 17 & 2013/4/15 & Landsat 8(OLI) \\
\hline 18 & $2014 / 5 / 20$ & Landsat 8(OLI) & 18 & $2014 / 5 / 20$ & Landsat 8(OLI) \\
\hline 19 & $2015 / 5 / 16$ & Landsat 8(OLI) & 19 & $2015 / 5 / 16$ & Landsat 8(OLI) \\
\hline 20 & $2016 / 4 / 23$ & Landsat 8(OLI) & 20 & $2016 / 4 / 23$ & Landsat 8(OLI) \\
\hline 21 & $2017 / 4 / 3$ & Landsat 8(OLI) & 21 & $2017 / 4 / 3$ & Landsat 8(OLI) \\
\hline 22 & $2018 / 3 / 5$ & Landsat 8(OLI) & 22 & $2018 / 3 / 5$ & Landsat 8(OLI) \\
\hline
\end{tabular}


The other primary field was to go into the relationship between surface material composition and lake surface area in basin. Due to the limitations of clouds and available time, we selected eight images about each basin during three decades from 1986 to 2018. These images are about four to five years apart. The months of the selected samples were concentrated from May to September because this part of the time was in a relatively stable state of summer vegetation and the amount of water was relatively abundant and easy to observe. The surface material composition data sources in the study are listed in Table 2.

Table 2. Remote sensing data source of study basin

\begin{tabular}{cccccc}
\hline & \multicolumn{2}{c}{ Dahai Basin } & \multicolumn{2}{c}{ Huangqihai Basin } \\
\hline Index & Time & Data Source & Index & Time & Data Source \\
\hline 1 & 1986.06 & Landsat 5(TM) & 1 & 1986.06 & Landsat 5(TM) \\
\hline 2 & 1993.09 & Landsat 5(TM) & 2 & 1993.09 & Landsat 5(TM) \\
\hline 3 & 1998.05 & Landsat 5(TM) & 3 & 1998.05 & Landsat 5(TM) \\
\hline 4 & 2001.08 & $\begin{array}{c}\text { Landsat 7(TM) } \\
\text { SLC-on }\end{array}$ & 4 & 2001.08 & $\begin{array}{c}\text { Landsat 7(TM) } \\
\text { SLC-on }\end{array}$ \\
\hline 5 & 2006.06 & Landsat 5(TM) & 5 & 2006.06 & Landsat 5(TM) \\
\hline 6 & 2010.06 & Landsat 5(TM) & 6 & 2010.06 & Landsat 5(TM) \\
\hline 7 & 2014.08 & Landsat 8(OLI) & 7 & 2014.08 & Landsat 8(OLI) \\
\hline 8 & 2018.05 & Landsat 8(OLI) & 8 & 2018.05 & Landsat 8(OLI) \\
\hline
\end{tabular}

\subsection{Calculation of the Lakes Area}

At present, there are many mature methods for extracting waters from optical images [26]. In this study, we chose a deep learning approach to process images. Deep learning is a domain that has been prevalent in recent years, especially in image classification. The continuous development of many high-quality models has brought higher accuracy to image classification. Considering the multispectral properties of Landsat images and the accuracy of deep learning models, we decided to use the Pyramid Scene Parsing Network (PSPNet) [27]. All experiments are conducted on Python with tensorflow-gpu 1.14.0 and the desktop computer we used is equipped with Windows 10, Intel(R) Core (TM) i7-6800K CPU and NVIDIA GeForce GTX 1080 8G GPU.

The traditional semantic analysis is only to obtain each pixel label of the known object, while ResNet is based on the semantic segmentation of scene analysis, which is to obtain the category label of all pixels in the image. Its integrated global features are more conducive to the accurate acquisition of target pixel tags, and its algorithm effect is better than traditional methods [27]. For this work, it is necessary to parse all the pixels in the whole image, so this method was adopted. However, this method has so far been used less in processing optical remote sensing images, so this experiment is a combination of optical image processing and computer vision methods.

The Pyramid Pooling Module combines features of four different scales Figure 3 [27]. The coarsest level highlighted in red square frame in the Figure 3 that is a single bin output generated by global pooling. The remaining three levels divide the input feature map into several different sub-areas, pool each sub-area, and finally combine the pooled single bins containing the location information. In the pyramid pooling module, different levels output different levels of feature maps. In order to maintain the weight of the global features, we employed a $1 \times 1$ convolution kernel after each pyramid level. If a level dimension is $\mathrm{N}$, this model can reduce the dimension of context feature to 1 / $\mathrm{N}$ of original feature. Then, the low dimensional feature map is directly upsampled to be the same as the original feature map by bilinear interpolation. Finally, the feature maps of different levels are stitched into the final pyramid pooled global features. 


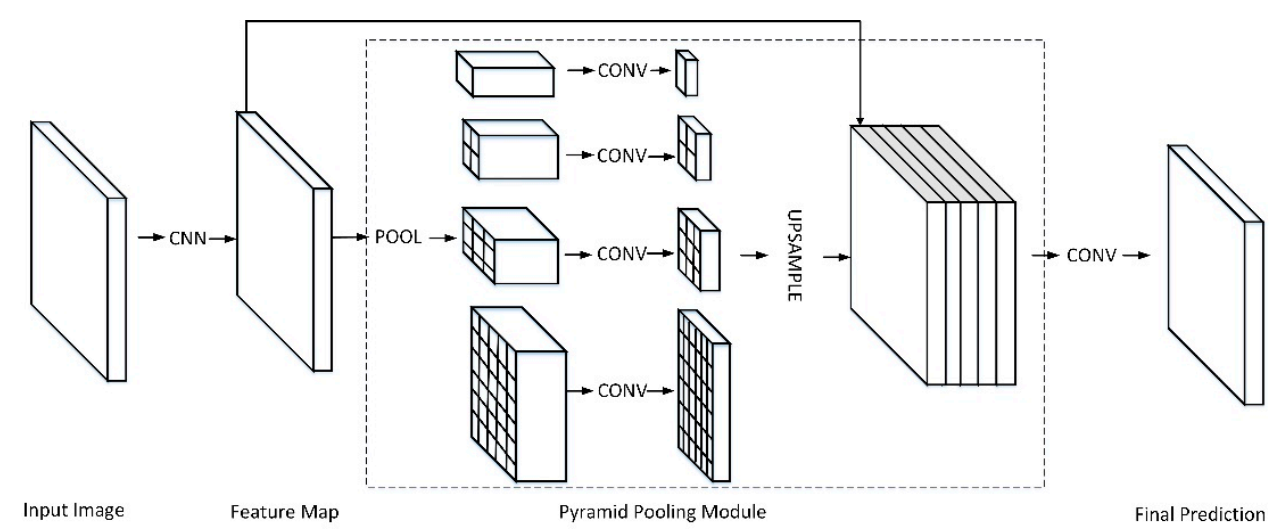

Figure 3. Neural network framework of PSPNet.

Though neural networks can provide good performance through deep pre-training, the increase of network depth may bring additional optimization difficulties for image classification. As a module in PSPNet, the ResNet is used to extract the feature map of the input image, and ResNet solves this problem by using a skip connection in each block. In the deep ResNet, the latter layer mainly learns the residuals thrown by the previous layer. Based on the original ResNet, PSPNet adds an auxiliary loss in the fourth stage in addition to the main branch of the final classifier using softmax loss. Finally, it adds weights to balance the auxiliary loss function. The two losses are then combined, using different weights to optimize the parameters together.

Therefore, for the input image in Figure 3, we used a pre-trained ResNet model with an extended network strategy to extract the feature map. The final feature size is $1 / 8$ of the input image, as shown above Figure 3. This work utilized the pyramid pooling module Figure 3 to obtain context information for the above feature map. The pyramid pooling module was divided into four levels, and the pooled kernel size is the whole, half, and small parts of the image. Eventually, they can be merged into global features. Then, in the final part of the Figure 3 module, this study connects the global features and the original feature map. Finally, the final prediction map was generated by convolutional layers in Figure 3.

Created data set is basic step, and we need to make a data set for the pre-processed Landsat images for training and testing [28]. The pseudo color with the combinations of Band Red, Band SWIR1, and Band SWIR2 are selected for the training process [29]. We selected eight images for each lake as training samples, and selected two images for the test sample as water data sets and manually labeled them. The annotated data set was then cut into 600 sample blocks of size $256 * 256 * 3$. There is no doubt that the number of these samples is too small to train. Therefore, we used the operations of pan, rotate, zoom, add noise, etc. to expand the number of image samples to 30,000.

Finally, in the experiment, adopt overall accuracy (OA) to assess the accuracy of water extraction area. The overall accuracy $(O A)$ can be obtained by the equation

$$
O A=\frac{T P+T N}{T P+F N+F P+T N}
$$

where $T P$ and $T N$ represent the pixel points whose labels are positive or negative and corresponding result is predicted to be the same while $F N$ and $F P$ represent the opposite. The $O A$ is about $98.9 \%$.

\subsection{Land Surface Classification}

Similarly, we employed PSPNet method in land surface classification. OA1 and OA2 represent the accuracy of land surface classification of Daihai basin and Huangqihai basin respectively. Classification accuracy of each category is listed in Table 3. 
Table 3. Overall accuracy for ground classification

\begin{tabular}{ccccccc}
\hline & Construction & Farmland & Woodland & Saline-alkali & Nudation & Water \\
\hline OA1 & $96.33 \%$ & $67.54 \%$ & $64.59 \%$ & $95.99 \%$ & $96.87 \%$ & $98.65 \%$ \\
\hline OA2 & $95.88 \%$ & $72.31 \%$ & $69.82 \%$ & $96.91 \%$ & $97.02 \%$ & $97.83 \%$ \\
\hline
\end{tabular}

Obviously, classification accuracy of farmland and woodland is low. We summarized the following reasons, including low training samples because of the general quality original images and farmland pixels and woodland pixels with too many similar features. In addition, the most important reason is over reclamation in forest areas produce complex forest-staggered areas with many error classification pixels. Thus, we had to establish an innovative means to distinguish between two similar cells.

We found those farmlands are relatively gentle area, while woodlands are relatively rugged through an investigation into the basin. In other words, the classification of farmland and woodland can convert to the recognition of land type. Based on this feature, we used ASTER GDEM $30 \mathrm{~m}$ data to look for the relationship between DEM and land type. In this part, the random unclassified pixel is selected as the central point and then extended around to form a large cell measuring $5 \times 5$ (Figure 4 ).

\begin{tabular}{|l|l|l|l|l|}
\hline 0 & 1 & 2 & 3 & 4 \\
\hline 1 & & & & \\
\hline 2 & & $\mu$ & & \\
\hline 3 & & & & \\
\hline 4 & & & & $\mathrm{i} \mathrm{j}$ \\
\hline \multicolumn{5}{|c|}{ Unclassified Pixel } \\
(a)
\end{tabular}

(a)

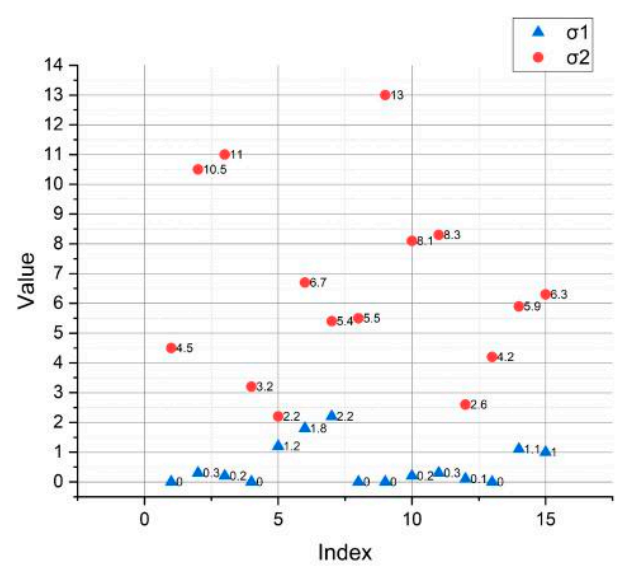

(b)

Figure 4. (a): Schematic diagram of unclassified pixel processing; (b) Standard deviation of farmland $(\sigma 1)$ and woodland $(\sigma 2)$ with DEM.

Taking the central point as the mean value and the peripheral point as the sample value, calculated the fluctuation of the target pixel and the surrounding pixel by the standard deviation of variation (1).

$$
\sigma=\frac{1}{25} \sum_{i=0, j=0}^{i=4, j=4}\left(X_{i j}-\mu\right),
$$

As showed in Figure 4, calculated $\sigma$ for farmland pixel and woodland pixel with 15 sample points for each in this work. In this picture, $\sigma 1$ and $\sigma 1$ represent farmland and woodland respectively. We draw the conclusion that the farmland pixel standard deviation value is generally less than two, and the pixel value of the woodland is the opposite. According to the above method, the OA of farmland and woodland classification is $93.7 \%$.

\section{Results}

\subsection{Variation for Lake Area}

After the above stage, construction of a yearly time-series of the water surface areas on Daihai Lake and Huangqihai Lake are displayed in Figure 5. 

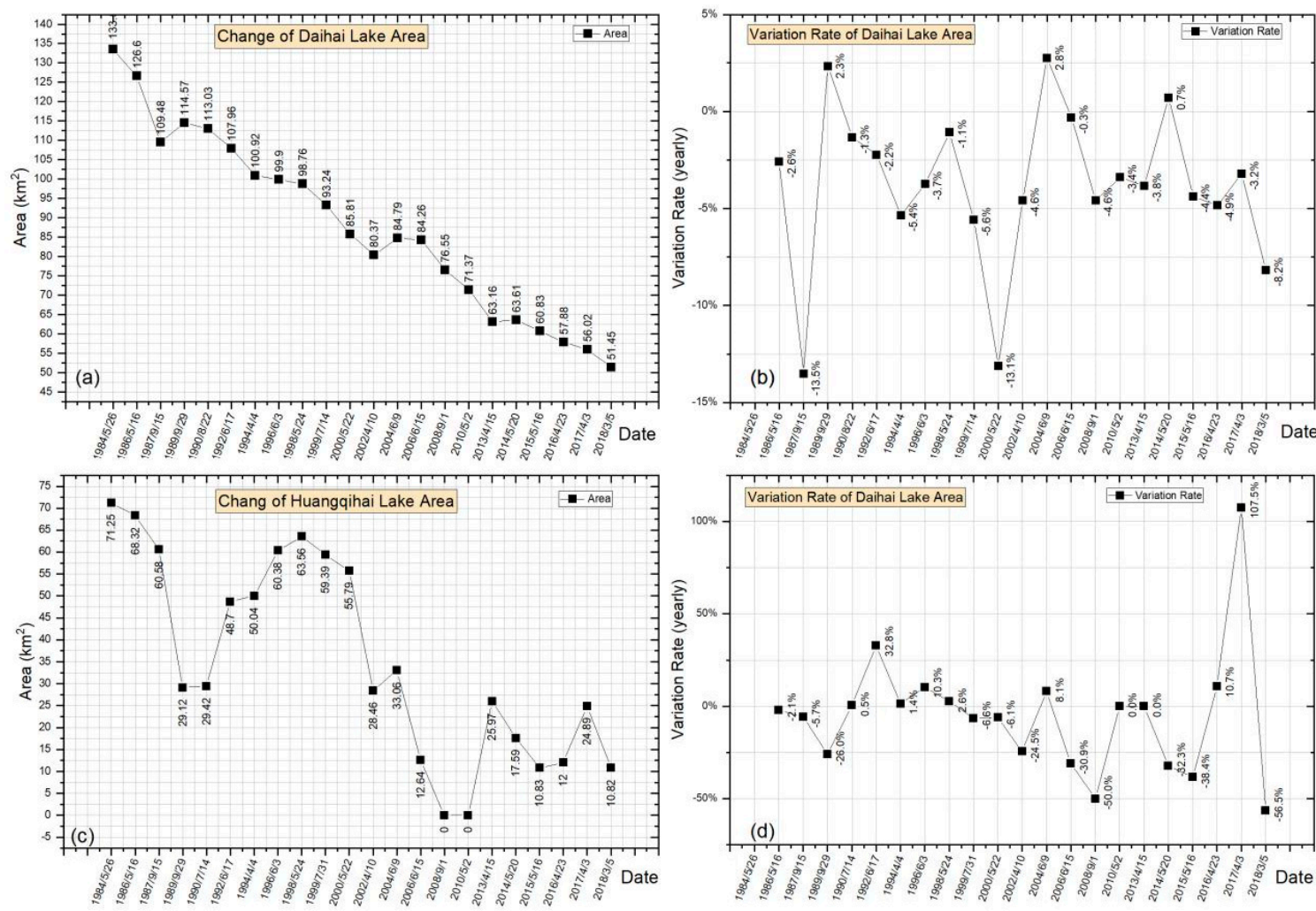

Figure 5. Time-series for variation of two lakes.

In this experiment, 22 pictures were used and a set of time-series data was made for each lake during from 1984 to 2018. Overall, the trend of surface area in Daihai Lake is declining. Daihai Lake area reached a maximum level of $133.5 \mathrm{~km}^{2}$ in 1984 and then declined at a rate of about three per cent. The entire lake area shrank to a staggering $82.05 \mathrm{~km}^{2}$, which accounted for $61.5 \%$ of the water surface in 1984. This shrinkage data is more than $30.3 \%$ of the total shrinking area of lakes in Inner Mongolia for nearly 30 years [6].

If Daihai Lake is a typical example of serious shrinkage of the water surface as considered, then the complete drying up of the Huangqihai Lake is regrettable. Overall, the water area of the Huangqihai Lake showed a downward trend until it ran dry completely. The area reached a peak of $71.25 \mathrm{~km}^{2}$ in 1984, but declined sharply in 1989, then rose to a rising trend from 1994 to 1998. After 1999, the lake fell sharply again until it dried up completely from 2006 to 2013. In the following years, water area has recovered slightly, but it is limited to the region that was located in the northwest and northeast of the lake. The recovery of the water area is mainly owing to the inflow of the river. There is a contrast between the two adjacent lakes. Daihai Lake still maintains a certain water quantity, but Huangqihai Lake has experienced drying up. This is important evidence that there are other sources of water supply in Daihai Lake and the decline of Daihai has been alleviated.

In the above paragraphs, we described the changes in the two lakes in terms of time distribution. Then, we continued to observe the characteristics of water surface changes for each lake from a spatial perspective. We selected some year images with significant changes and drew diagrammatic sketch of the water surface change on Daihai Lake and Huangqihai Lake respectively. Figures 6 and 7 show the spatial changes of each lake. 


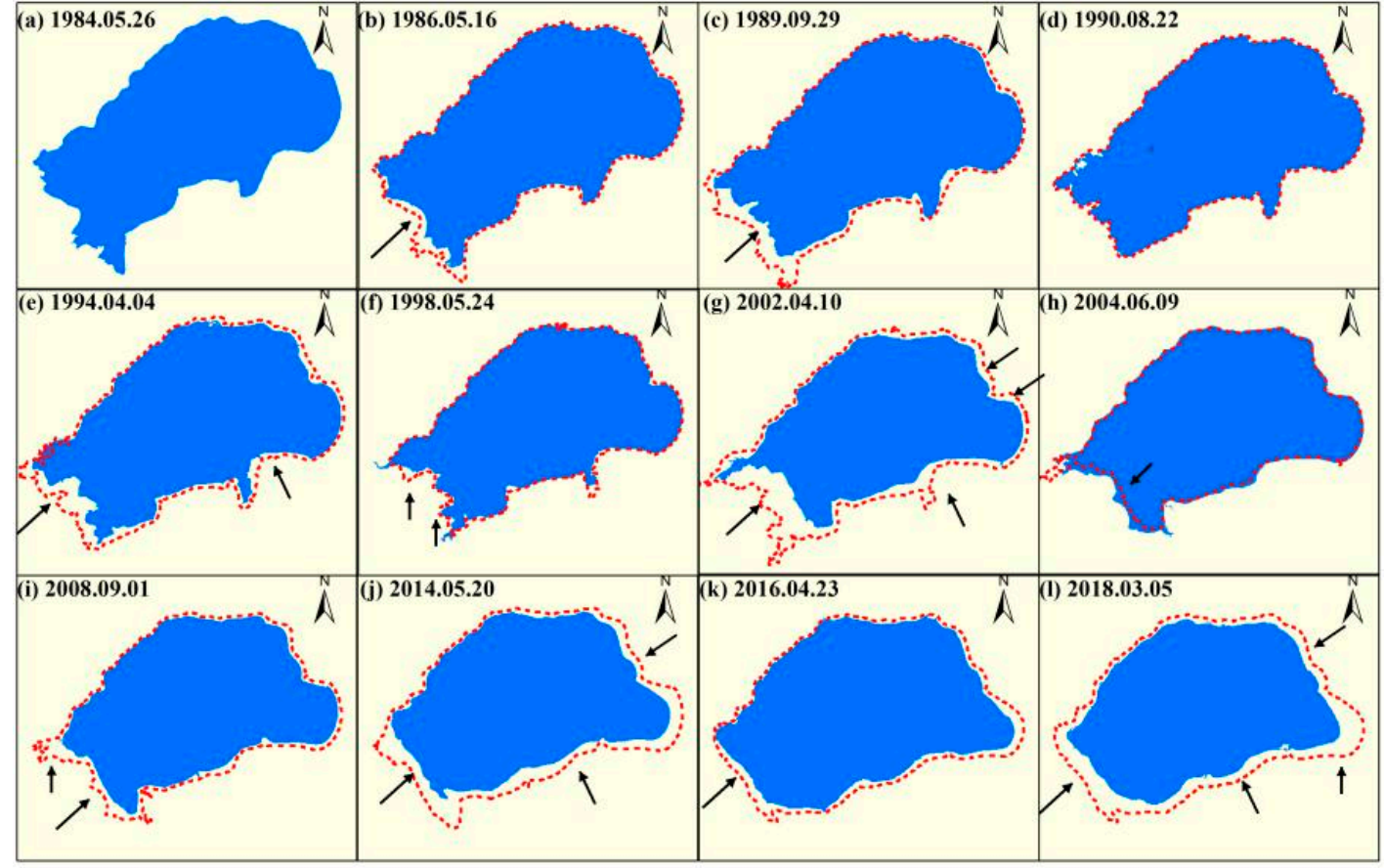

Figure 6. Spatial variation of Daihai Lake surface.

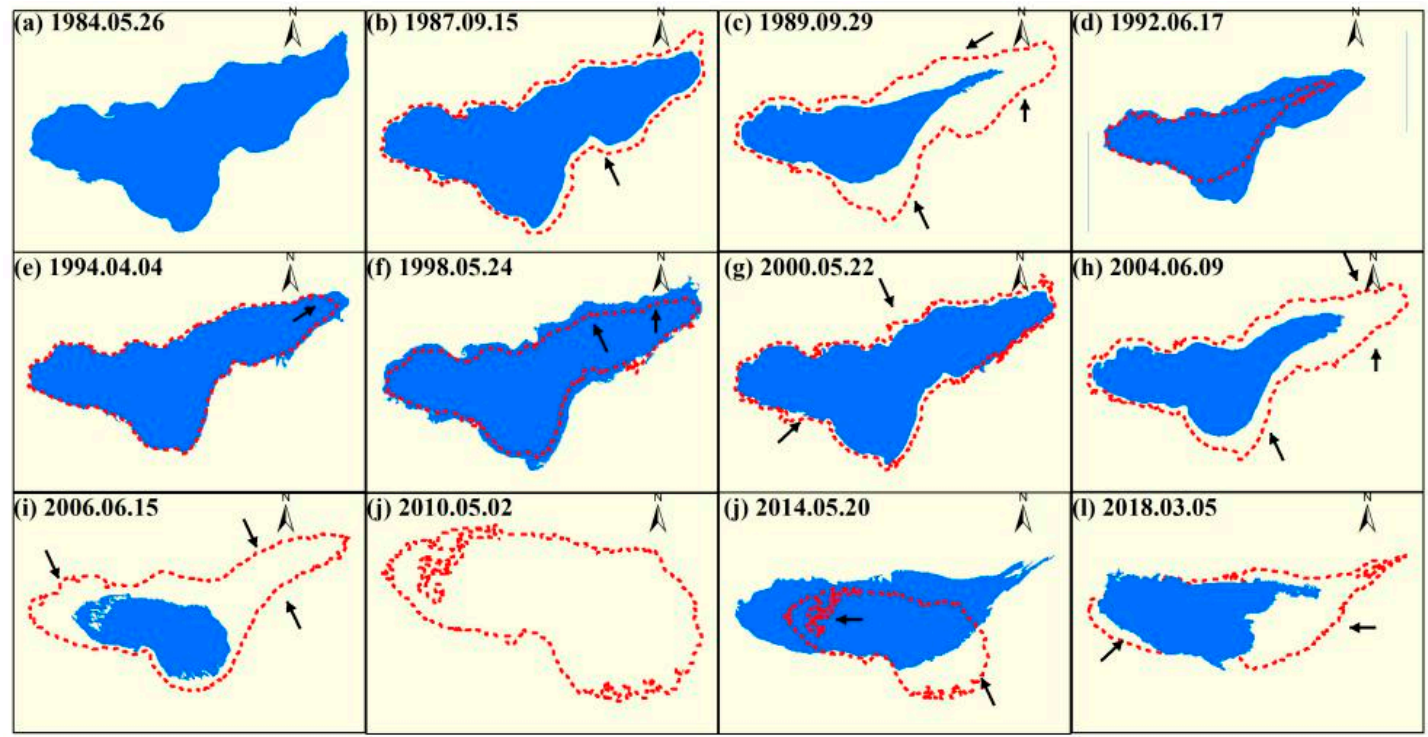

Figure 7. Spatial variation of Huangqihai Lake surface.

Figure 6 shows that the whole Daihai Lake mainly shrank from south to north, while the north and northeast also showed a small shrinkage. Before 1989, the lake shrank mainly in the south, and the water surface in the north and northeast was stable. During the later 1990s, the south and northeast of Daihai Lake began to shrink sharply. After 2004, the main shrinking parts of water surface have gathered around in the south and northeast of the lake.

Compared with the steady shrinkage of Daihai Lake, the water surface of Huangqihai Lake fluctuates more violently. Before 1994, the surface of the lake shrank only slowly inward along the shoreline. However, between 1994 and 2002, the southern and northeastern parts of Huangqihai Lake showed drastic contraction. From 2002 to 2008, the lake dried up for the first time. This result is basically consistent with the previous results [30]. Although the lake recovered in the northwest region between 2014 and 2018, as shown in Figure 1, it was just the result of the river flowing into the lake. 


\subsection{Ground Composition}

Using the above methods, this experiment carries on the ground pixel classification to Daihai basin and Huangqihai basin. In order to be more suitable for the study of the causes of lake water changes, the surface categories are divided into six categories. Specific classified data are shown in Tables 4 and 5.

Table 4. Statistics of ground classification in Daihai basin.

\begin{tabular}{ccccccc}
\hline \multicolumn{7}{c}{ Daihai basin Ground classification $\mathbf{( k m}^{\mathbf{2}} \mathbf{c}$} \\
\hline Date & Construction & Farmland & Woodland & Nudation & Water & Saline-alkali \\
\hline 1986.06 & 1.39 & 182.72 & 72.73 & 1927.00 & 138.94 & 0.00 \\
\hline 1993.09 & 2.66 & 123.21 & 95.14 & 1975.89 & 116.98 & 0.00 \\
\hline 1998.05 & 3.06 & 349.93 & 222.41 & 1635.72 & 103.68 & 0.00 \\
\hline 2001.08 & 5.90 & 230.25 & 19.61 & 1972.26 & 84.74 & 0.00 \\
\hline 2006.06 & 6.54 & 134.93 & 102.21 & 1961.41 & 99.97 & 9.48 \\
\hline 2010.06 & 7.19 & 145.89 & 115.46 & 1971.03 & 75.56 & 0.00 \\
\hline 2014.08 & 50.89 & 291.80 & 64.41 & 1837.62 & 70.48 & 0.00 \\
\hline 2018.05 & 86.99 & 377.24 & 145.40 & 1642.66 & 59.98 & 4.65 \\
\hline
\end{tabular}

Table 5. Statistics of ground classification in Huangqihai basin.

\begin{tabular}{ccccccc}
\hline \multicolumn{7}{c}{ Huangqihai Basin Ground classification $\left.\mathbf{( k m}^{2}\right)$} \\
\hline Date & Construction & Farmland & Woodland & Nudation & Water & Saline-alkali \\
\hline 1986.05 & 40.30 & 107.45 & 23.35 & 4221.00 & 78.30 & 0.00 \\
\hline 1993.09 & 53.86 & 68.04 & 10.28 & 4226.29 & 60.60 & 47.63 \\
\hline 1998.05 & 67.35 & 317.75 & 108.33 & 3904.10 & 82.97 & 0.00 \\
\hline 2001.08 & 76.23 & 694.73 & 81.77 & 3572.57 & 55.20 & 0.00 \\
\hline 2006.09 & 79.67 & 71.15 & 17.84 & 4265.09 & 28.24 & 2.29 \\
\hline 2010.07 & 89.86 & 197.69 & 19.65 & 4137.20 & 25.23 & 11.07 \\
\hline 2014.05 & 123.78 & 269.59 & 32.54 & 3961.07 & 58.91 & 0.00 \\
\hline 2018.05 & 234.38 & 632.50 & 184.37 & 3375.68 & 31.08 & 50.49 \\
\hline
\end{tabular}

The area of the construction increased in Daihai basin year by year. Before 2010, the area was stable relatively and expanded 10-fold from 2010 to 2018 (Figure 8). Distribution of the construction are mainly located at Liangcheng county in southwest of the lake, which began to scatter around the lake and the county after 2010. The farmland area was stable about $150 \mathrm{~km}^{2}$ until 2010, but the area of 1998 showed a three times increase compared to 1993. Because the local government adopted the project of the expansion of planting area in order to increase economic income. The woodland area has been stable relatively between $50 \mathrm{~km}^{2}$ and $150 \mathrm{~km}^{2}$ except in 1998. The local government's excessive afforestation plan gave rise to the burst increase of the water consumption in the basin. Regrettably, the growth resulted in excessive water consumption in the region, which cannot sustain the growth of these trees. This is the reason why trees withered in a large area in 2001. The nudation area, accounting for more than $85 \%$ of the whole basin, includes bare mountains and arable land without growing crops, which is enough to show that the soil and water conservation capacity of the land is low. In addition to the main Daihai Lake, the water area also includes reservoirs, dams, and some water in the river, which shows a downward trend. Saline-alkali area are more volatile, mainly around the lake and part of the dry beach, which is related to direct human production and vegetation cover at that time. 


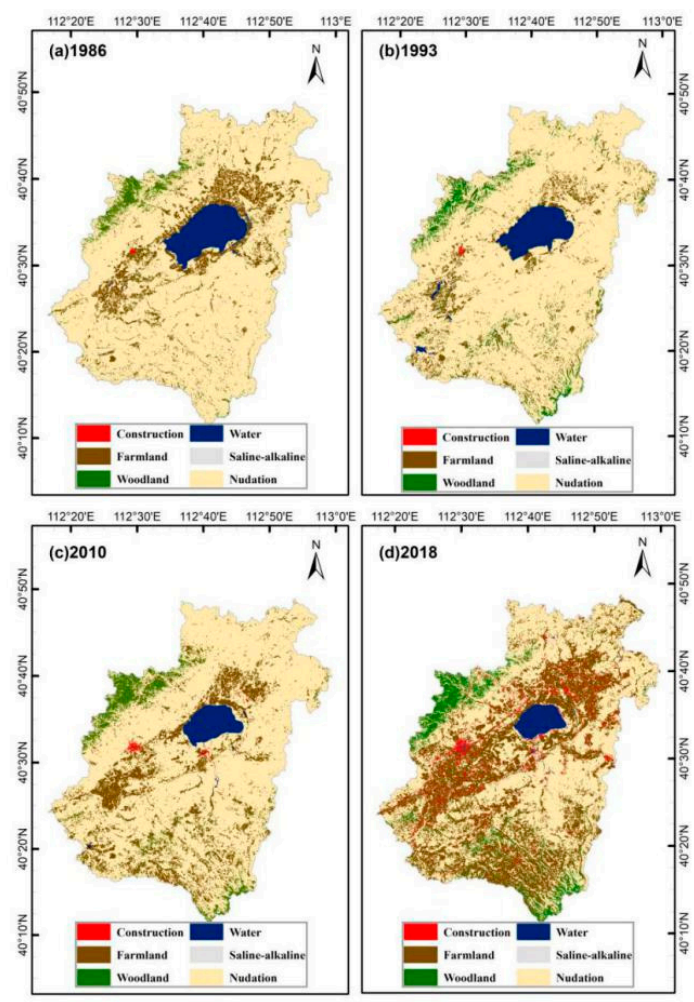

Figure 8. Ground classification of Daihai basin.

Because there are three larger cities in the Huangqihai basin and the economy is more developed than Daihai basin (Figure 9). Thus, the construction area is much larger than that in the Daihai basin. Similarly, the building area also had a huge increase in the Huangqihai basin after 2010. Farmland area fluctuated before 2010. In 1998, there was still a burst of growth, unlike Daihai basin, which lasted until 2001, but the area did not drop sharply until 2006. Next, there has been a steady upward trend. Woodland area has remained at a low level relatively except in 1998, 2001, and 2018. Great fluctuations are evident in excessive human intervention. Nudation reached previous level again in 2006 after a decline in 1999. The water area of the basin has been declining because of the gradual drying up of the Huangqihai Lake. It rebounded in 2014, but fell again in 2018. Saline-alkali land is mainly saline-alkali land formed by the residual salt of bare land after the removal of lake. With the change of lake water area and artificial intervention, the area of saline-alkali land is also changing.
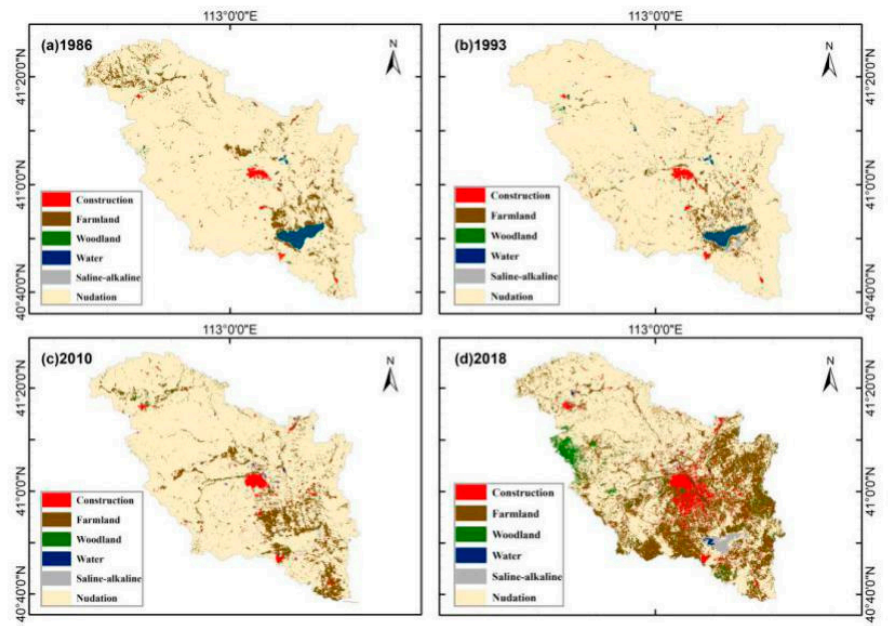

Figure 9. Ground classification of Huangqihai basin. 


\section{Discussion}

\subsection{Qualitative Analysis of the Recharge Process}

There are two possible sources of groundwater for recharge to lakes. One of them, it comes from local precipitation. The local precipitation assimilates into the groundwater by soil infiltration. The other one, groundwater of recharge lakes comes from external water. Because the lakes are located on the fault zones with transmission channels of water, the exogenous water continuously transports to the lakes and surrounding aquifers through the fault zones.

Generally, the common lake will expand to a maximum in the annual rainy season and shrink to a minimum in the dry season. However, we used remote sensing to make an experiment. Here, the experiment also used the above-mentioned the deep learning method to extract lakes in the target region. Based on the number of remote sensing images in the same year, the randomly selected sample year is 2000. Then the work selected one day of observation month as the representative image of the month, and continued to select the representative image of the next month about one month apart. This work found that the opposite phenomenon has occurred in the Daihai Lake. The lake area is smallest in the rainy season (June to September) and largest in the dry season (January to May and October to December) (Figure 10). In dry season, there was no precipitation to supplement the lake water while the lake water area increased. This indicates that the evaporation of the lake surface is greater than the amount of water entering the lake and the main recharge of the lake is derived from groundwater. The ground water recharge comes from the leakage of the fault zone in this area. However, the above situation did not occur in the experiment of the Huangqihai Lake. During the previous dry season, the lake area continued to decline and the arrival of the rainy season eased the situation. In the next dry season, there was no rainfall and the lake area fell again (Figure 10). This shows that the water supply of the Huangqihai Lake mainly comes from the precipitation and runoff in the basin. The recharge method of the Daihai Lake belongs to the second case and this of Huangqihai Lake is the first case. This is an important evidence to indicate that Daihai Lake receives external water supply to alleviate the lake shrinkage.
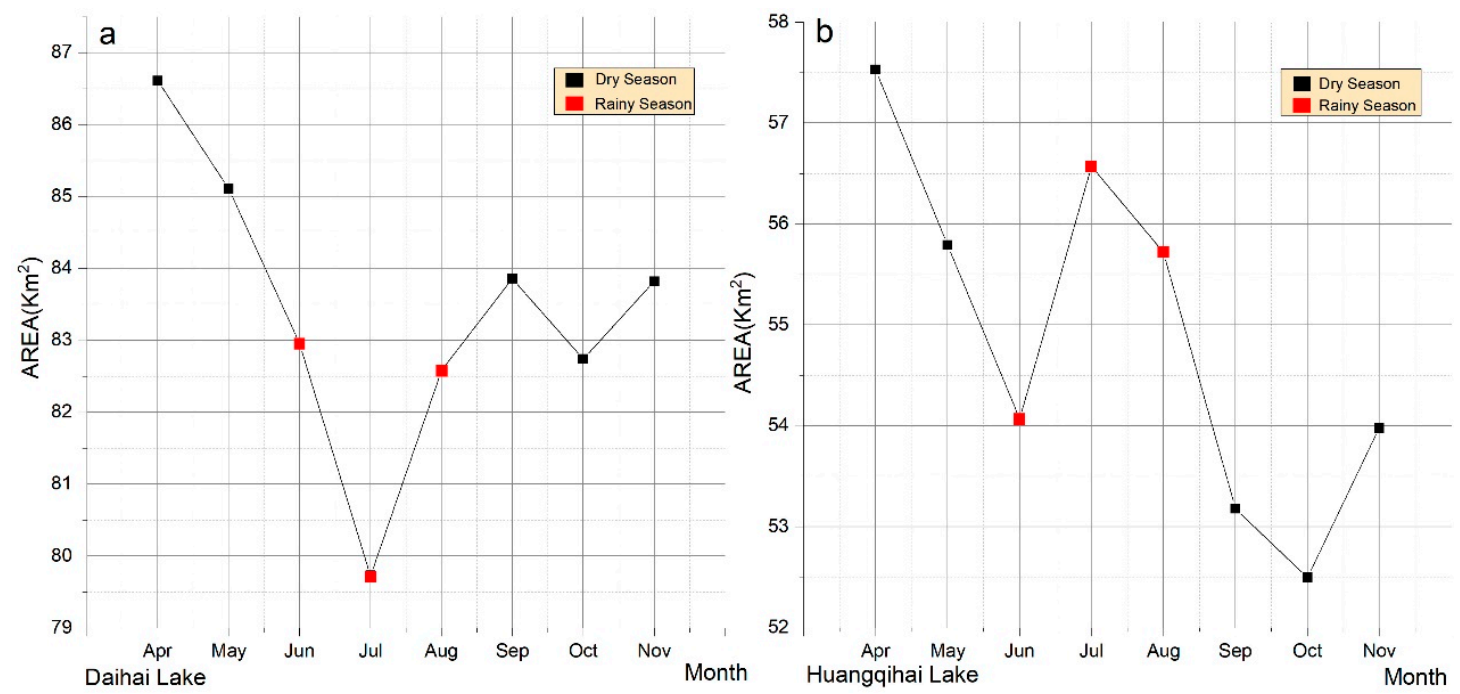

Figure 10. Lake area change in 2000

In order to further verify our experimental results, a hydrological method was also used. The soil infiltration test showed that the local precipitation cannot enter the groundwater in Daihai basin, because the unsaturated soil water does not reach the maximum water-holding capacity of field (WHCF) and the soil moisture content is in a loss state. In other word, the necessary condition for precipitation infiltration is above the maximum WHCF [14]. We studied the evapotranspiration (ET) of 
this region is about $395 \mathrm{~mm}$ [31] (www.cnern.org.cn), which is basically the equal to the local average annual precipitation of $384 \mathrm{~mm}(\mathrm{DH})$ and $374 \mathrm{~mm}(\mathrm{HQH})$. That is to say, the precipitation of the basin is basically evaporated, and cannot form groundwater of the basin through infiltration. We used remote sensing method to analyze the causes of the lake area change, and we also used soil chemistry and surface evapotranspiration method to verify the results. These experimental results indicated that there is exogenous water supply to Daihai Lake (Figure 11).

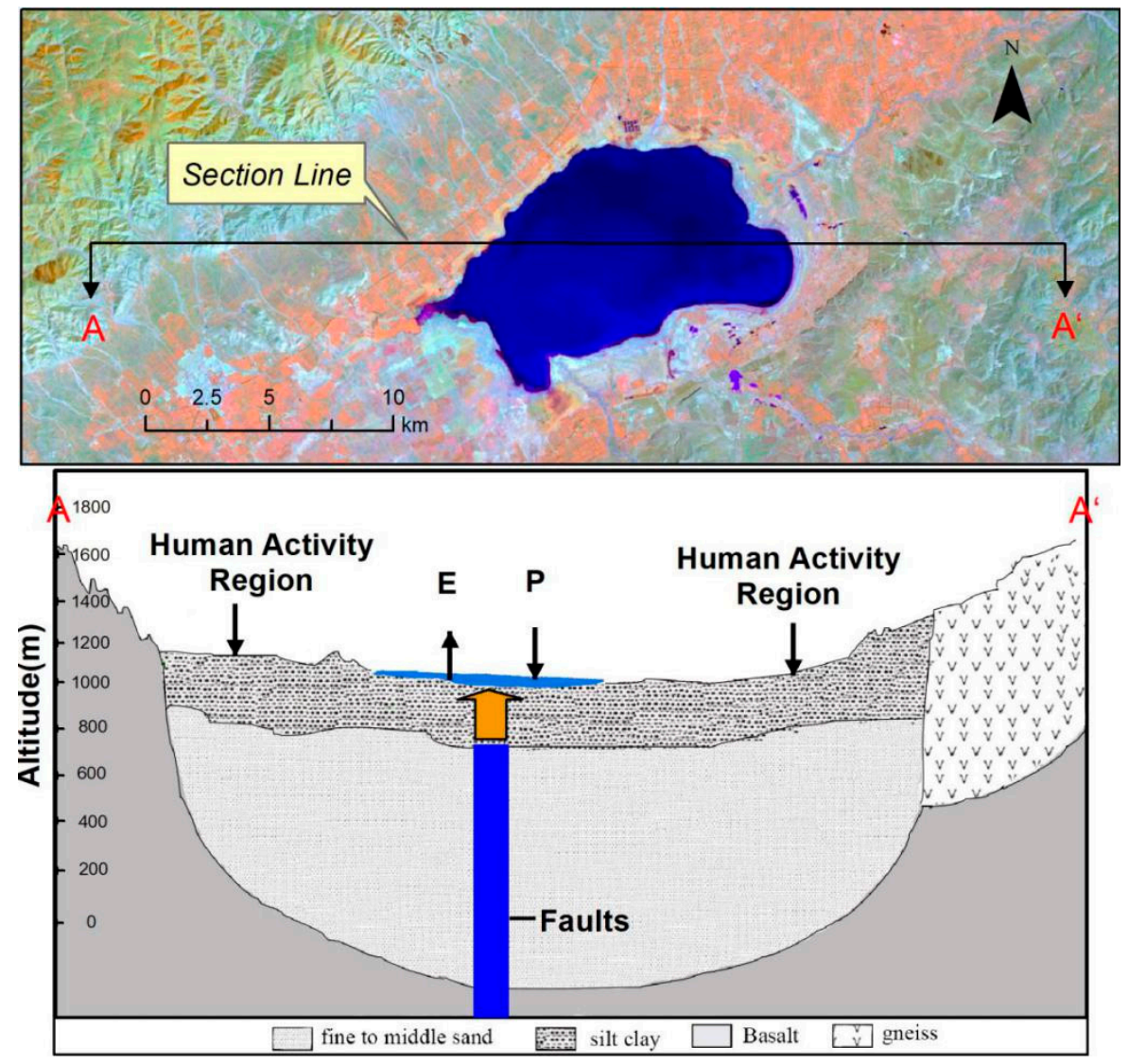

Figure 11. Daihai Lake receives external groundwater recharge.

The above three methods confirm the existence of external groundwater recharge in Daihai Lake, and whether there will be external water recharge in Huangqihai Lake, which is only $64 \mathrm{~km}$ away from Daihai Lake. If so, why did the Huangqihai Lake eventually dry up in 2008? Hydrological and isotope experiments showed that the deep underground wells and springs in the Huangqihai basin are the same as those in the Daihai Basin, and the surface springs eventually converge into rivers to supply the Huangqihai Lake. However, because of the artificial construction of river dams to intercept water sources for daily life, economic and agricultural, the lake has lost its recharge.

\subsection{Quantitative Analysis of Water Supply and Consumption}

The above analysis shows that the Daihai Lake received external groundwater recharge while the Huangqihai Lake received no external groundwater supply. The quantitative value of groundwater recharge was calculated along with the balance relationship between recharge and emission, based on the analysis [32]. If the water content of a basin maintains a dynamic balance, it must be equal to the water flowing in and out. Since the Daihai basin is a closed watershed, the water volume changes of the basin can be expressed through the Daihai Lake.

Firstly, we introduced the related indicators in the next work. The region is special and the crops species are relatively scarce. We use the annual statistical yearbooks of the region to estimate 
the agricultural water consumption (AWC) for the different crop areas in these years [33-35]. Flood irrigation is the main practice for farmland in Daihai basin, so the water requirement of crops needs to be converted into the total irrigation water consumption. The irrigation efficiency of this area is about $62.7 \%$ [36]. We used agricultural irrigation consumption (AIC) as one of the groundwater estimation indicators. Agricultural water consumption in the region accounted for $54.3 \%$ of the total water consumption of human activity (TWCHA) in 2003, which makes us to estimate TWCHA by AIC (excluding power consumption of power plants). The local government introduced a power plant that needed to use the lake water for water cooling for economic development after 2005, which increased the evaporation of the lake water directly. Annual water consumption (PPWC) reached $1.206^{*} 10^{7} \mathrm{~m}^{3}$ according to the estimation. In this experiment, the annual water volume reduction (WVR) was estimated using the annual water level relationship and the area obtained by remote sensing.

For the water flowing into the Daihai Lake, external water, precipitation, and runoff are the main resources. The hypothesis that rainfall infiltrates into groundwater recharge lakes has already been negated through the special phenomenon of change of the lake area in different seasons by remote sensing and has proven that this conclusion is a reliable the work of water chemistry. The runoff volume of the basin is only $6^{*} 10^{3} \mathrm{~m}^{3}$ yearly [13]. The supply of lake water is less, so it can be ignored. Therefore, water flowing into the lake can be reduced to surface precipitation and external groundwater (DGR). The water flowing out of the Daihai Lake, first of all the direct annual evaporation water consumption (EWC) the lake was calculated by evaporation of the basin, which is need to multiply conversion coefficient (0.55) [37]. Then, the Daihai Power Plant needs to consume lake water every year. Finally, there is about $9.12^{*} 10^{7} \mathrm{~m}^{3}$ of groundwater in the basin itself and this part of the groundwater has been extracted by people (TWCHA). Although the surface precipitation cannot infiltrate to form groundwater, the lake replenishes lost water of the basin to maintain the water balance in the basin. So, this element of artificial consumption is also part of the lake water consumption. The calculation method of parts of the indicators are more intuitive in Figure 12.

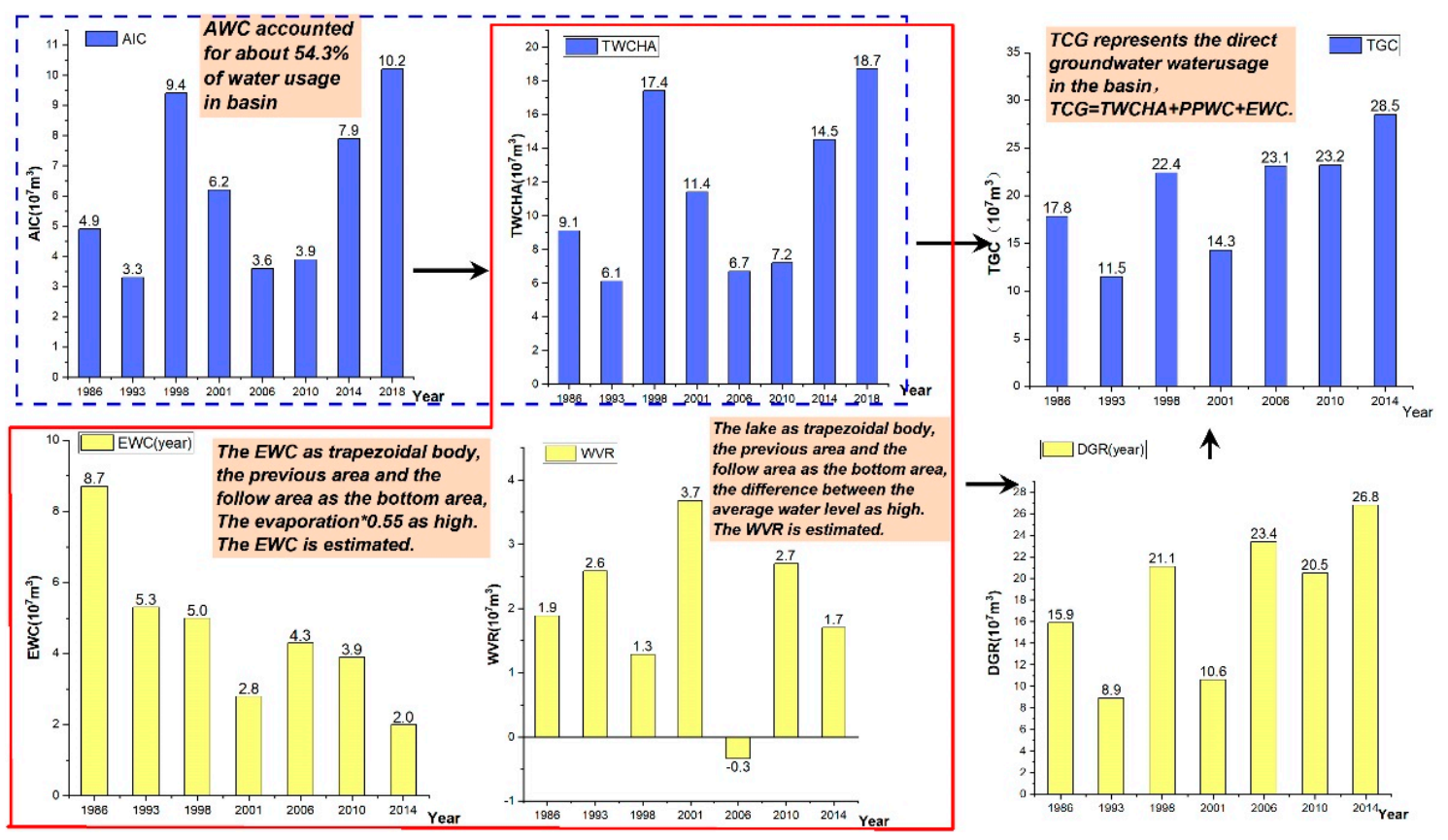

Figure 12. Water consumption and recharge in Daihai Basin.

All of these inflows and outflows are change of lake water volume (WVR). The resulting equation is

$$
\begin{aligned}
& W V R=P P W C+E W C+\text { TWCHA }- \text { DGR. } \\
& \text { DGR }=\text { PPWC + EWC + TWCHA - WVR. }
\end{aligned}
$$


The recharge volume of exogenous groundwater is not a fixed value calculated by the water chemistry method Table 6. At the same time, in order to better observe the proportion of water consumption and the variation, we presented the whole calculation results in the form of histogram (Figure 12). The reason of inconsistency is that the calculation method is to use the surface area to calculate EWC in this paper. The area of the Daihai Lake after 2000 year is about $100 \mathrm{~km}^{2}$ less than that of 1960s, so the calculation of evaporation loss will also be reduced. However, this value is maintained range $0.89^{*} 10^{8} \mathrm{~m}^{3}$ to $2.68^{*} 10^{8} \mathrm{~m}^{3}$ and the average annual replenishment is $1.81^{*} 10^{8} \mathrm{~m}^{3}$, which is close to the $1.8^{*} 10^{8} \mathrm{~m}^{3}$ calculated by the water chemistry method. The method just measured the recharge amount for one year while our method measured the recharge amount for many years. The experimental results in this paper are more reliable. Finally, the total annual consumption of groundwater is calculated to be an average of $2.0^{*} 10^{8} \mathrm{~m}^{3}$. This work quantitatively calculated the recharge of groundwater to Daihai Lake, which provided substantial evidence for groundwater to alleviate the shrinkage of the lake. This annual groundwater consumption is slightly larger than the average annual external groundwater recharge. This imbalance state indirectly proves that lakes are shrinking every year.

Table 6. Water consumption and recharge in Daihai Basin $\left(10^{7} \mathrm{~m}^{3}\right)$

\begin{tabular}{|c|c|c|c|c|c|c|c|c|}
\hline Date & AWC & AIC & TWCHA & PPWC $^{1}$ & WVR $^{2}$ & EWC & DGR $^{3}$ & TGC $^{4}$ \\
\hline 1986.06 & 3.1 & 4.9 & 9.1 & 0.0 & 1.9 & 8.7 & 15.9 & 17.8 \\
\hline 1993.09 & 2.1 & 3.3 & 6.1 & 0.0 & 2.6 & 5.3 & 8.9 & 11.5 \\
\hline 1998.05 & 5.9 & 9.4 & 17.4 & 0.0 & 1.3 & 5.0 & 21.1 & 22.4 \\
\hline 2001.08 & 3.9 & 6.2 & 11.4 & 0.0 & 3.7 & 2.8 & 10.6 & 14.3 \\
\hline 2006.06 & 2.3 & 3.6 & 6.7 & 1.2 & -0.3 & 4.3 & 23.4 & 23.1 \\
\hline 2010.06 & 2.5 & 3.9 & 7.2 & 1.2 & 2.7 & 3.9 & 20.5 & 23.2 \\
\hline 2014.08 & 4.9 & 7.9 & 14.5 & 1.2 & 1.7 & 2.0 & 26.8 & 28.5 \\
\hline 2018.05 & 6.4 & 10.2 & 18.7 & 1.2 & 1 & 1 & 1 & 1 \\
\hline
\end{tabular}

Although, we concluded that the area change of the Huangqihai Lake is mainly related to the huge evaporation in the region. Next, this result needs further proof. Because of the irregular lake shape and the lack of the lake water level data, we cannot get the WVR value. So, we can still explain from other aspects. Based on the agricultural planting data and the classification results of this experiment, we obtained AWC value. Then, TWCHA was estimated by the proportion of agricultural water usage in Ulanchab city for many years. Based on the annual runoff data of Jining Hydrological Station of Bawang River (Figure 1), it is concluded that the average annual runoff of the Bawang River has been about $6.3^{*} 10^{6} \mathrm{~m}^{3}$ in the past 30 years. Due to many dams in the upper reaches of the river, the inflow of the river into the lake is much lower than this value and other secondary inflow runoff is similar. Therefore, the runoff into the lake can be neglected.

It can be seen from the Table 7 that the water consumption of human activities has been increasing since 1993. In 2001, the unexpected planting events accelerated the consumption of groundwater resources, which prevented the rapid recharge of Huangqihai Lake. In addition, the increase of human activities has also increased the consumption of groundwater resources. Ultimately, the groundwater level will decrease. Because the average depth of the lake was only three $\mathrm{m}$ [38], the lake cannot be recharged by groundwater. Besides, saline-alkali land hindered the infiltration of groundwater, which led to the drying up of the lake eventually in 2008. Due to the rapid decrease of lake surface area in the lake, it is obviously different from Daihai Lake and there is no direct groundwater to recharge to it. 
Table 7. Water consumption and recharge in Huangqihai Basin $\left(10^{7} \mathrm{~m}^{3}\right)$

\begin{tabular}{cccccc}
\hline Date & AWC & AIC & TWCHA(year) & EWC(year) & TCG \\
\hline 1986.05 & 1.1 & 1.7 & 2.1 & 11.4 & 13.5 \\
\hline 1993.09 & 0.7 & 1.1 & 1.3 & 4.1 & 5.4 \\
\hline 1998.05 & 3.1 & 5.0 & 6.2 & 8.2 & 14.4 \\
\hline 2001.08 & 6.8 & 10.8 & 13.4 & 4.0 & 17.4 \\
\hline 2006.09 & 0.7 & 1.1 & 1.5 & 5.3 & 6.8 \\
\hline 2010.07 & 1.9 & 3.1 & 4.3 & 3.0 & 7.3 \\
\hline 2014.05 & 2.6 & 4.2 & 6.0 & 2.9 & 8.9 \\
\hline 2018.05 & 6.2 & 9.9 & 14.1 & $/$ & $/$ \\
\hline
\end{tabular}

\subsection{Reasons for Lake Degradation}

There are two mainstream views on lake shrinkage. The one is that climate change has mainly led to varying degrees of shrinkage of lakes [39-42], and the other one is excessive human activities is main reason [43]. As we know from the above, the reasons for the decline of these two lakes are climate and perceived factors. Using the above experimental data, we calculated the proportion of the annual human water consumption to the two basins.

Evaporation precipitation difference (EPD) is evaporation minus precipitation (Figure 13). Next, we replaced Daihai Basin's EPD and Huangqihai Basin's EPD with DH EPD and HQH EPD solely. Through the investigation of evaporation and rainfall data, we can clearly find that the DH and HQH EPD value are all positive. In other words, the evaporation has always been greater than precipitation in this area, so the water of lakes is in continuous consumption state. Furthermore, we calculated the area of lakes and Pearson correlation coefficients of EPD for 0.83(DH) and 0.77(HQH). Therefore, it is concluded that evaporation is one of the causes of lake water shrinkage. Because the area of Daihai Lake is not consistent with the trend of broken line of DH EPD before 2000, we thought that the reduction of the Daihai Lake water is not only related to the evaporation in the basin, but also may have other factors after 2000. HQH EPD is different from DH EPD. Compared with Daihai Lake, the changes of the Huangqihai Lake area and the trend of the HQH EPD are more undulate. The evaporation loss value is huge in Huangqihai basin. Since 1984, the EPD has increased and the lake area has gradually decreased. In 1990, the EPD value reached the maximum and the lake area presented, correspondingly, the lowest value in this period. After 1990, the EPD decreased and the lake area gradually increased. In 1999, the EPD reached its peak again and the lake area responded very closely to the change. Later, the EPD values remained low, but it seemed that the lake could not stop shrinking and eventually dried up completely in 2008. Excessive evaporation in the basin was the main reason of the drying up of the lake before 2001, but other factors may be lead to the changes after 2001.

The recharge period of groundwater determined is about 30 years by tritium [44]. Since the seasonal variation of recharge flow has been homogenized for 30 years, the recharge flow rate of external water can be regarded as a constant. Therefore, the source of the lake can be simplified as precipitation and relatively stable external water. Furthermore, precipitation and groundwater are stable for recharge source of the lake, and evaporation is stable for consumption source of the lake in the three decades. So, excluding the above two stabilizing factors, the reduction of two lake area should have other fluctuation reasons. It should be related to the large amount of groundwater pumped for agricultural irrigation, industrial production and domestic water.

Before 1998, the climate change in Daihai basin was the main factor leading to the reduction of Daihai Lake area Table 8. After 1998, with the development of economy and the expansion of population, human activities have become the main factor affecting the change of Daihai Lake, and the situation is getting worse and worse. Comparatively speaking, the factors of Huangqihai Lake are more complex. Among them, human activities consume more water than climate before 2001, and climate consumes more 
water than human activities after 2001 except 2006. This conclusion is consistent with the phenomenon of EPD, and indicates that human activities have more influence on the lake changes since 2001. Therefore, on the whole, the shrinkage of the Huangqihai Lake is a combination of human activities and climate.
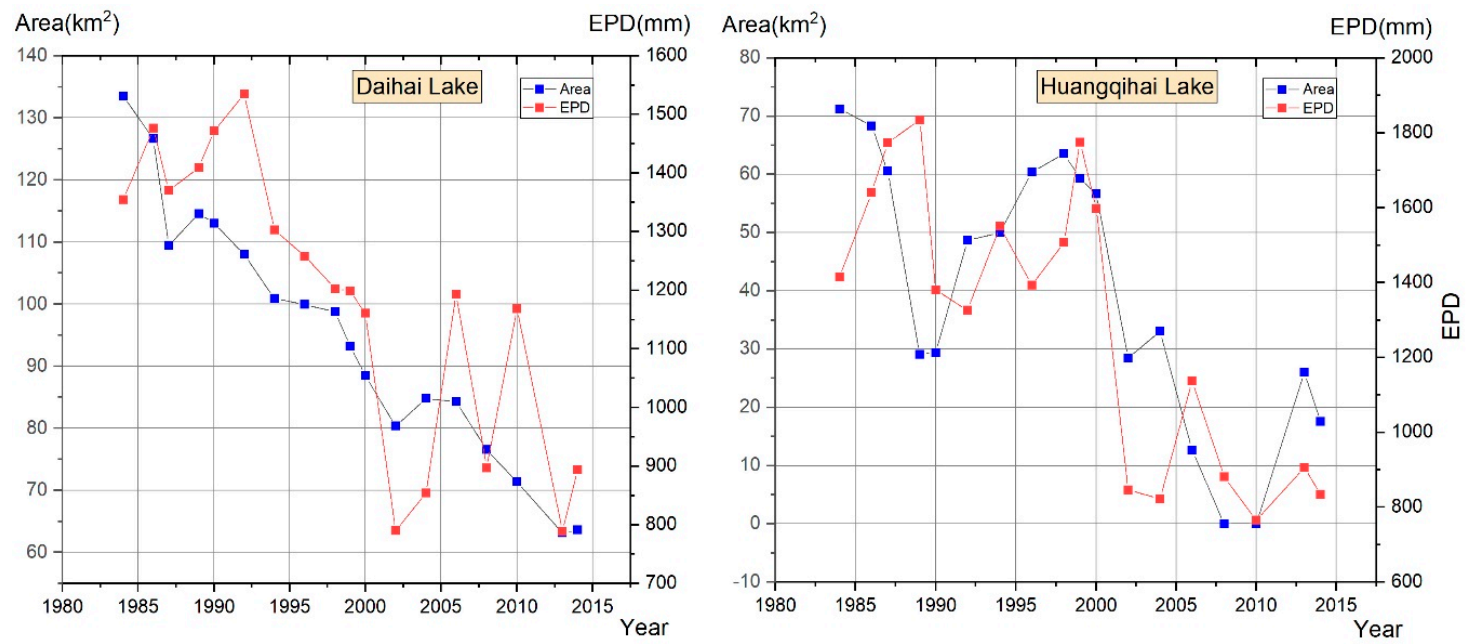

Figure 13. Area, precipitation, and evaporation of the lakes difference in basin.

Table 8. Proportion of water consumption in two basins (\%)

\begin{tabular}{cccccccc}
\hline \multicolumn{7}{c}{ Daihai Basin } \\
\hline Date & $\mathbf{1 9 8 6 . 0 6}$ & $\mathbf{1 9 9 3 . 0 9}$ & $\mathbf{1 9 9 8 . 0 5}$ & $\mathbf{2 0 0 1 . 0 8}$ & $\mathbf{2 0 0 6 . 0 6}$ & $\mathbf{2 0 1 0 . 0 6}$ & $\mathbf{2 0 1 4 . 0 8}$ \\
\hline Human & 47.7 & 40.2 & 72.7 & 71.6 & 77.2 & 80.8 & 89.5 \\
\hline Climate & 52.3 & 59.8 & 27.3 & 28.4 & 22.8 & 19.2 & 10.5. \\
\hline \multicolumn{7}{c}{ Huangqihai Basin } & \\
\hline Date & $\mathbf{1 9 8 6 . 0 5}$ & $\mathbf{1 9 9 3 . 0 9}$ & $\mathbf{1 9 9 8 . 0 5}$ & $\mathbf{2 0 0 1 . 0 8}$ & $\mathbf{2 0 0 6 . 0 9}$ & $\mathbf{2 0 1 0 . 0 7}$ & $\mathbf{2 0 1 4 . 0 5}$ \\
\hline Human & 15.5 & 24.6 & 43.1 & 76.9 & 22.4 & 58.8 & 67.3 \\
\hline Climate & 84.5 & 75.4 & 56.9 & 23.1 & 77.6 & 41.2 & 32.7 \\
\hline
\end{tabular}

\subsection{Environment Effects and Measures}

The inland closed lake environment is very sensitive to the feedback of climate change [45], we need to assess the impact of lakes on the surrounding environment. It can be seen Figure 5 that although both lakes have suffered from different degrees of shrinkage, the feedback from the Daihai Lake area to the whole basin is positive because the lake can maintain more water (Figure 14). We calculated these proportions and the proportion of buildings of Daihai basin is $1.19 \%$ lower than that of Huangqihai basin average year. In other words, that is the water consumption of agriculture and industry in Daihai basin will be lower than that of Huangqihai basin. The proportion of the total water area of Daihai basin is $2.47 \%$ higher than that of Huangqihai basin yearly. That is to say, the Daihai basin has more abundant water resources than the Huangqihai basin. More water resources directly led to an increase $2.64 \%$ and $2.70 \%$ of the farmland and woodland of Daihai basin compared to the Huangqihai Basin average every year. There is more woodland and farmland, so the proportion of nudation of Daihai basin is $11.80 \%$ less than the average of Huangqihai yearly. All in all, more water maintains a better ecological environment in the basins. 

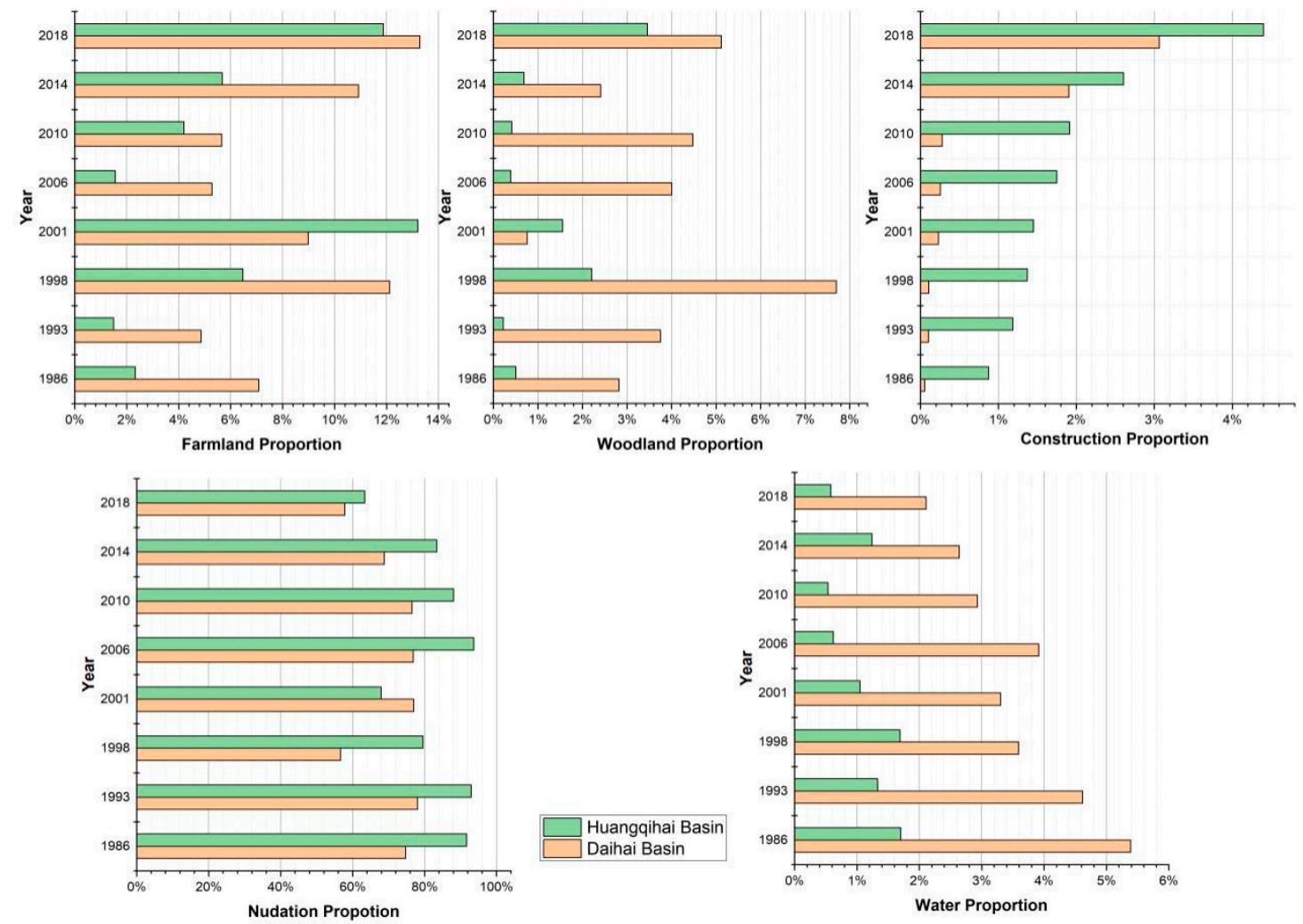

Figure 14. Proportion of various land types in the basin.

Many lakes are shrinking in arid and semi-arid areas [46]. People try to use various methods to alleviate and even change the process. It is not clear whether the effect of the method is effective or ineffective. We found out the reasons for the shrinkage of lakes, in order to implement effective measures rather than carrying out transformation over rules of nature. Therefore, the behavior of returning farmland and saving local water usage can alleviate the shrinkage of the lake. Fortunately, the local government seems to be aware of the crisis of the lake shrinkage and has been carrying out the whole basin activities of returning farmland and woodland since 2016. We still need to observe how it works. Although this plan can alleviate the shrinkage of Daihai Lake, it seems that the surface area of Daihai Lake cannot be restored to former area without more foreign water supply. Hence, the local government proposed to divert the Yellow River to supply Daihai Lake. Whether this project will affect the ecological environment of other places once it is implemented deserves our attention.

The results of the above analysis indicated that excessive groundwater extraction for agricultural irrigation and industrial production is the main reason for the lake decline. Although exogenous groundwater recharge to Daihai Lake, it cannot maintain such a huge consumption of people. Let alone Huangqihai Lake, which has no huge amount of exogenous water supplement. Cognac is normal state for the lake in the future. Therefore, reducing or even stopping the extraction of groundwater is an important measure to alleviate this trend.

\section{Conclusions}

In this paper, the recharge resources of two lakes were explored based on remote sensing data and site data, and we studied to the reason for degradation of the lakes. We found that Daihai Lake is supplied with external groundwater, which alleviated the decline of the lake in arid areas owing to the existence of a water diversion structure. Huangqihai Lake lacks recharge of external groundwater directly, and humans pumped too much groundwater from the basin, resulting in the lake drying up. Most of the lakes in the Inner Mongolia Plateau are arid or semi-arid climatic conditions, but there are still many lakes. These lakes are basically dependent on direct or indirect recharge of exogenous 
groundwater. However, these lakes are facing degradation in different degree. Although exogenous water can alleviate the decline of these lakes, the increasing human demand for water cannot prevent these lakes from disappearing eventually. These lakes play an extremely important role in semi-arid fragile ecosystems. People seem to be aware of the urgency of this problem, actions are being taken to curb the lake shrinkage and even to restore the lake to some extent, which we need to keep watch. Due to the limitation of the data quantity of remote sensing images, this paper did not calculate the material around the surface entirely according to the year of the lake area Figure 5 change, but selected the phenomenon of image observation about every five years, which may bring deviation to the experimental results. Besides, this paper cannot estimate the annual direct loss volume of the Huangqihai Lake due to the lack of the lake water level change data, which will make the conclusion insufficient. In the future, we will continue to monitor the changes of these lakes and whether human rescue measures can serve as a model for their protection.

Author Contributions: Conceptualization, J.C. and J.L.; Methodology, J.C. and J.L.; Software, J.L.; Validation, J.C., J.L., and Q.W.; Formal analysis, J.W.; Investigation, J.C. and J.L.; Resources, J.C.; Data curation, J.L.; Writing-original draft preparation, J.L., J.C., and N.L.; Writing-review and editing, N.L. and J.C.; Visualization, Q.W. and J.W.; Supervision, N.L.; Project administration, J.C.; Funding acquisition, J.C. and N.L. All authors have read and agreed to the published version of the manuscript.

Funding: This research was funded in part by the National Key R\&D Program of China (no. 2017YFB0502700), in part by the National Natural Science Foundation of China (no. 61771183, 61601437), in part by the Fundamental Research Funds for the Central Universities (no. 2016B07114), in part by the Plan of Science and Technology of Henan Province (no. 192102210082), in part by the Youth Talent Lifting Project of Henan Province (no. 2019HYTP006), and in part by the China Postdoctoral Science Foundation (no. 2013M541035).

Acknowledgments: Thanks for Jiansheng Chen to furnish with professional idea on water hydrochemistry work; thanks for Zhanyang Zhang that provided assistance for Figure 11.

Conflicts of Interest: The authors declare no conflict of interest.

\section{References}

1. Crighton, E.J.; Elliott, S.J.; Upshur, R.; van der Meer, J.; Small, I. The Aral Sea disaster and self-rated health. Health Place 2003, 9, 73-82. [CrossRef]

2. Lioubimtseva, E.; Henebry, G.M. Climate and environmental change in arid Central Asia: Impacts, vulnerability, and adaptations. J. Arid Environ. 2009, 73, 963-977. [CrossRef]

3. Sarch, M.-T.; Birkett, C. Fishing and Farming at Lake Chad: Responses to Lake-Level Fluctuations. Geogr. J. 2000, 166, 156-172. [CrossRef]

4. Williams, W.D. Salinisation: A major threat to water resources in the arid and semi-arid regions of the world. Lakes Reserv. Res. Manag. 1999, 4, 85-91. [CrossRef]

5. Xiao, X.; Ojima, D.S.; Parton, W.J.; Chen, Z.; Chen, D. Sensitivity of Inner Mongolia grasslands to climate change. J. Biogeogr. 1995, 22, 643-648. [CrossRef]

6. Tao, S.; Fang, J.; Zhao, X.; Zhao, S.; Shen, H.; Hu, H.; Tang, Z.; Wang, Z.; Guo, Q. Rapid loss of lakes on the Mongolian Plateau. Proc. Natl. Acad. Sci. USA 2015, 112, 2281-2286. [CrossRef]

7. Zhang, P.; Deng, Q.; Zhang, G.; Ma, J.; Gan, W.; Min, W.; Mao, F.; Wang, Q. Active tectonic blocks and strong earthquakes in the continent of China. Sci. China Ser. D Earth Sci. 2003, 46, 13-24. [CrossRef]

8. Zhang, G.M.; Ma, H.S.; Wang, H.; Wang, X.L. Boundaries between active-tectonic blocks and strong earthquakes in the China mainland. Chin. J. Geophys. Chin. Ed. 2005, 48, 602-610. [CrossRef]

9. Jie, B.; Xi, C.; Liao, Y.; Hui, F. Monitoring variations of inland lakes in the arid region of Central Asia. Front. Earth Sci. 2012, 6, 147-156. [CrossRef]

10. Chiew, F.H.S.; McMahon, T.A. Groundwater Recharge from Rainfall and Irrigation in the Campaspe River Basin. Aust. J. Soil Res. 1991, 29, 651-670. [CrossRef]

11. Jiansheng, C.; Bichen, J.I.; Zhen, L.I.U.; Zhiwei, Z.; Shiyin, Z. Isotopic and hydro-chemical evidence on the origin of groundwater through deep-circulation ways in Lake Daihai region, Inner Mongolia plateau. J. Lake Sci. 2013, 25, 521-530. [CrossRef] 
12. Dong, C.; Wang, N.a.; Chen, J.; Chen, H.; Chen, L.; Li, Z.; Ma, N. New observational and experimental evidence for the recharge mechanism of the lake group in the Alxa Desert, north-central China. J. Arid Environ. 2016, 124, 48-61. [CrossRef]

13. Qun, H.; Jiahu, J. Analysis of Water Level Descent in Daihai Lake. J. Lake Sci. 1999, 11, 304-310. [CrossRef]

14. Wang, T.; Chen, J.S.; Xu, Y.; Zhan, L.C.; Huang, D.W. Isotopes and hydrochemistry of Daihai Lake recharging sources, Northern China. J. Radioanal. Nucl. Chem. 2017, 312, 615-629. [CrossRef]

15. Xiao, J.; Xu, Q.; Nakamura, T.; Yang, X.; Liang, W.; Inouchi, Y. Holocene vegetation variation in the Daihai Lake region of north-central China: A direct indication of the Asian monsoon climatic history. Quat. Sci. Rev. 2004, 23, 1669-1679. [CrossRef]

16. Jin, D.; Rui, G.; Yong, W.; Shihong, Z.; Peiyi, Y.; Zhenqing, C.; Zhili, Z. Magnetic Fabric Study of Late Holocene Sediments in Huangqihai Lake, Inner Mongolia and its Sedimentary Significance. Acta Geol. Sin. 2013, 87, 186-196. [CrossRef]

17. Xiaoqiang, L.; Jie, Z.; Ji, S.; Chengyu, W.; Hongli, Z.; Qianli, S. Vegetation history and climatic variations during the last $14 \mathrm{ka}$ BP inferred from a pollen record at Daihai Lake, north-central China. Rev. Palaeobot. Palynol. 2004, 132, 195-205. [CrossRef]

18. Zhang, J. Timing and possible forcing mechanisms of Huangqihai Lake fluctuations in semi-arid northern China since the late Glacial. Quat. Int. 2012, 279-280, 559. [CrossRef]

19. Huazhang, L.; Qingsi, L.; Jiaxing, W. Study of evolution of Huangqihai and Daihai Lakes in holocene in inner mongolia plateau. J. Lake Sci. 1992, 4, 31-39. [CrossRef]

20. Peng, Y.; Xiao, J.; Nakamura, T.; Liu, B.; Inouchi, Y. Holocene East Asian monsoonal precipitation pattern revealed by grain-size distribution of core sediments of Daihai Lake in Inner Mongolia of north-central China. Earth Planet. Sci. Lett. 2005, 233, 467-479. [CrossRef]

21. Sun, Q.; Wang, S.; Zhou, J.; Chen, Z.; Shen, J.; Xie, X.; Wu, F.; Chen, P. Sediment geochemistry of Lake Daihai, north-central China: Implications for catchment weathering and climate change during the Holocene. J. Paleolimnol. 2010, 43, 75-87. [CrossRef]

22. Jin, Z.; Li, F.; Cao, J.; Wang, S.; Yu, J. Geochemistry of Daihai Lake sediments, Inner Mongolia, north China: Implications for provenance, sedimentary sorting, and catchment weathering. Geomorphology 2006, 80, 147-163. [CrossRef]

23. Xu, L.; Liu, Y.; Sun, Q.; Chen, Z.; Chen, J.; Cheng, P. Climate change and human occupations in the Lake Daihai basin, north-central China over the last 4500years: A geo-archeological perspective. J. Asian Earth Sci. 2017, 138, 367-377. [CrossRef]

24. Zhang, J.; Jia, Y.; Lai, Z.; Long, H.; Yang, L. Holocene evolution of Huangqihai Lake in semi-arid northern China based on sedimentology and luminescence dating. Holocene 2011, 21, 1261-1268. [CrossRef]

25. Frantz, D.; Röder, A.; Stellmes, M.; Hill, J. An Operational Radiometric Landsat Preprocessing Framework for Large-Area Time Series Applications. IEEE Trans. Geosci. Remote Sens. 2016, 54, 1-16. [CrossRef]

26. Jia, P.; Zhang, M.; Yu, W.; Shen, F.; Shen, Y. Convolutional neural network based classification for hyperspectral data. In Proceedings of the 2016 IEEE International Geoscience and Remote Sensing Symposium (IGARSS), Beijing, China, 10-15 July 2016; pp. 5075-5078. [CrossRef]

27. Zhao, H.; Shi, J.; Qi, X.; Wang, X.; Jia, J. Pyramid Scene Parsing Network. In Proceedings of the 2017 IEEE Conference on Computer Vision and Pattern Recognition (CVPR), Honolulu, HI, USA, 21-26 July 2017; pp. 6230-6239. [CrossRef]

28. Shelhamer, E.; Long, J.; Darrell, T. Fully Convolutional Networks for Semantic Segmentation. IEEE Trans. Pattern Anal. Mach. Intell. 2016, 39, 640-651. [CrossRef]

29. Zhang, T.; Tang, H. A Comprehensive Evaluation of Approaches for Built-Up Area Extraction from Landsat OLI Images Using Massive Samples. Remote Sens. 2018, 11. [CrossRef]

30. Chen, M.; Liu, J. Historical trends of wetland areas in the agriculture and pasture interlaced zone: A case study of the Huangqihai Lake Basin in northern China. Ecol. Model. 2015, 318, 168-176. [CrossRef]

31. Chen, S.; Chen, J.; Lin, G.; Zhang, W.; Miao, H.; Wei, L.; Huang, J.; Han, X.-G. Energy balance and partition in Inner Mongolia steppe ecosystems with different land use types. Agric. For. Meteorol. 2009, 149, 1800-1809. [CrossRef]

32. Dyer, J. A GIS-Based Water Balance Approach Using a LiDAR-Derived DEM Captures Fine-Scale Vegetation Patterns. Remote Sens. 2019, 11, 2385. [CrossRef] 
33. Xiao, J.; Liu, Z.; Duan, A.; Liu, Z. Water Production Function during the Whole Growing Stage for Main Crops in China. Chin. Agric. Sci. Bull. 2008, 3, 430-434.

34. Penman, H. Natural Evaporation From Open Water, Bare Soil and Grass. Proc. R. Soc. A Math. Phys. Eng. Sci. 1948, 193, 120-145. [CrossRef]

35. Guoyan, P.; Zhu, O.; Qunying, L.; Qiang, Y.; Jishun, W. Water Consumption of Seven Forage Cultivars Under Different Climatic Conditions in the North China Plain. J. Resour. Ecol. 2011, 2, 74-82.

36. Jiang, L.; Yang, Y.; Shang, S. Evaluation on irrigation efficiency of irrigation district in arid region based on evapotranspiration estimated from Remote Sensing data. Nongye Gongcheng Xuebao Trans. Chin. Soc. Agric. Eng. 2013, 29, 95-101. [CrossRef]

37. Shunjun, H.; Changyan, T.; Yudong, S.; Bing, C.; Fang, W. Conversion Coefficient of Water Surface Evaporation in Tarim River Basin. J. Desert Res. 2005, 5, 649-651.

38. Dong, J.; Wang, Y.; Zhang, S.H.; Fu, X.M.; Yao, D.L. Grain size analysis of Holocene lacustrine sediments in the Huangqihai Lake of Inner Mongolia and its sedimentological significance. Geol. Bull. China 2014, 33, 1514-1522.

39. Fang, L.; Tao, S.; Zhu, J.; Liu, Y. Impacts of climate change and irrigation on lakes in arid northwest China. J. Arid Environ. 2018, 154, 34-39. [CrossRef]

40. Liang, K.; Yan, G. Application of Landsat Imagery to Investigate Lake Area Variations and Relict Gull Habitat in Hongjian Lake, Ordos Plateau, China. Remote Sens. 2017, 9, 1019. [CrossRef]

41. Liu, J.; Kang, S.; Gong, T.; Lu, A. Growth of a high-elevation large inland lake, associated with climate change and permafrost degradation in Tibet. Hydrol. Earth Syst. Sci. 2010, 14, 481-489. [CrossRef]

42. Yao, J.Q.; Chen, Y.N.; Zhao, Y.; Yu, X.J. Hydroclimatic changes of Lake Bosten in Northwest China during the last decades. Sci. Rep. 2018, 8, 9118. [CrossRef]

43. Gibson, J.J.; Prowse, T.D.; Peters, D.L. Partitioning impacts of climate and regulation on water level variability in Great Slave Lake. J. Hydrol. 2006, 329, 196-206. [CrossRef]

44. Chen, J.S.; Wang, Q.Q. A discussion of groundwater recharge sources in arid areas of North China. Water Resour. Prot. 2012, 28, 1-8. [CrossRef]

45. Ma, M.; Wang, X.; Veroustraete, F.; Dong, L. Change in area of Ebinur Lake during the 1998-2005 period. Int. J. Remote Sens. 2007, 28, 5523-5533. [CrossRef]

46. Zedler, J.B.; Kercher, S. Wetland resources: Status, trends, ecosystem services, and restorability. Annu. Rev. Environ. Resour. 2005, 30, 39-74. [CrossRef] 